\title{
Residents' partnering in public housing basic infrastructure provision and maintenance: a strategy for satisfactory public housing provision
}

\author{
OKOYE, Chinedu Oguejiofo \\ Department of Environmental Management Nnamdi Azikiwe University, Awka, Nigeria.
}

\begin{abstract}
This paper discusses residents' partnering in public housing basic infrastructure facilities as a strategy for satisfactory public housing provision. It was motivated by the result of the evaluation of the status of basic infrastructure facilities in our public housing estates considering the rapid relocation of occupants to private estates and neighborhoods and on the premise that these are model housing estates. It identifies the quantity, quality, maintenance and level of residents' satisfaction on the basic infrastructure facilities which are roads, sanitary and non-sanitary facilities, water, electricity, and solid waste disposal facilities. A total of five hundred and six households representing seventy-two point three percent of the total households in five habited estates in Awka-Nigeria, viz Udoka, Ahocol I and II, Iyiagu and Real estates were examined through a fifty-four item questionnaire and analyzed. Results obtained reveal generally that though the quantity of basic infrastructure facilities provided in the estates are fairly adequate, the quality and maintenance of these facilities are poor. The residents of the estates are generally dissatisfied with the provisions. The paper recommends a strategy for the involvement of the public housing estates residents in public housing basic infrastructure provision.
\end{abstract}

Keywords: Residents' partnering; Public housing; Infrastructure provision; Basic infrastructure.

\section{Introduction}

Infrastructure has an indispensable positive role in development [1]. The World Development Report, 1994 correlates a one percent increase in gross domestic product with a one percent increase in infrastructure stock across all countries [1]. There has been much written on the role of urban infrastructure [2, 3, 4]. Besides its function of raising the productivity of labour and capital as an "unpaid factor of production" infrastructure contributes to the welfare of households [5]. Improvements in infrastructure services can have the beneficial effect of increasing household's real income and quality of life. [6] asserted that the improvement of welfare and production capacity through availability of reliable and sustainable infrastructure is regarded as one of the most important objectives of, as well as means to economic development.

Historically, public housing provision rested in the hands of private developers. The government concerned itself with various levels of development controls, provision and maintenance of urban services. Municipal councils, through the instrument of bye-laws controlled land use and ensured standards of building coverage; provide access and essential services to properties, and maintained health and safety standards. Private developers erected buildings within the limits of existing zoning regulations and as their capital and profit expectations allowed. [7] pointed out that there was a dogmatic adherence to outdated Town Planning Laws and Building Codes formulated along the lines of the British standards prevailing at the time.

Housing provision by the public sector was the responsibility of the Regional Administrations of which the scope and consequent impact was small. The Federal Government did not accept housing as part of its social responsibility until the Third $(1975-80)$ and the Fourth $(1981$ - 1985) National Development plans, [8,9]. Hitherto housing was lumped with Town Planning that was regarded as a low priority sector.

The civilian Government of 1979 made housing provision the nucleus of the government programme. Over 40,000 housing units were to be constructed throughout the country with an average of 2,000 units in the states for the low-income group but government effort was thwarted due to some logistics and political reasons. Some of the buildings were abandoned halfway; some completed without anybody occupying them, hence vandalization or dilapidation and total collapse in some cases. Government initial policies were geared towards government active participation in the provision of housing for all income groups. By 1980, an actual physical achievement in terms of housing units completed was $19 \%$ in Lagos and $13 \%$ in other parts of the country [10].

The National Sites and Services programme was adopted by the Federal Government in 1986 as a viable alternative for housing delivering through increased supply of serviced plots at affordable costs. The aim of the programme was to create easy access to land development facilities which had for long hindered home ownership. The programme involved the provision of serviced land for housing development and commercial activities in a well layout and planned environment. Such services would include roads, drains, water supply, 
electricity and other municipal services. This programme was supposed to make available the basic infrastructure need in our housing estates to provide some comfort to living. Since the commencement of the programme in 1986 to the end of 1999, only about 20,000 plots have been allocated in about 20 states of the Federation [11]. Six billion, nine hundred and eighty six million naira (N6.986b) was required to complete the on-going site and services project. The proper implementation of site and services scheme would provide adequate basic infrastructure in our public housing estates for satisfactory living.

Our public housing estates generally and especially those in Awka, capital of Anambra State are experiencing various forms of infrastructure deterioration. These housing estates are Udoka, Ahocol, Iyiagu and Real estates. While the basic infrastructure are not provided in some estates from design inception, others are either lacking maintenance thereby not meeting the required need or disliked by the residents. Our public housing estates which are government initiated, planned and managed purpose to provide sufficient and adequate housing to the people ought to be models of housing provision especially in basic infrastructure facilities. Despite what obtains in the nation's general infrastructure facilities, there is high expectation that our public housing estates should be a place to take clue. The satisfaction of the residents of the public housing estates should therefore be a priority. This paper seeks to provide a solution to public housing basic infrastructure provision and maintenance as a result of the high level of dissatisfaction by the public housing residents.

\section{Research methods}

The study population was the entire 700 households obtained from the 506 habited houses in the chosen public housing estates in Awka. Udoka housing estate has 177, 236 at Ahocol think home estates 1 and 2,129 at Iyiagu housing estate and 132 at Real housing estates.

The above population figure was drawn from a pilot survey of the study estates since the details of the 2006 National Population and Housing Census were yet to be released as at the time of this study. The total number of persons living in the estates was estimated to be 3,930 using an average of 6 persons per household.

However, one household per house was examined. This gave a total of 506 households representing 72.3\% of the total house holds. In the entire households in Udoka, 91.5\% was sampled, 63.1\% in Ahocol 1 and $2,48.8 \%$ in Iyiagu and $83.5 \%$ in Real estate. A purposive sampling type of non probability sampling technique was used to select the older or oldest household where there is more than one in a house. This is with the understanding that responses from such a household should serve as a representation of the condition or true picture of basic infrastructure facilities provided in that house. A random sampling technique was used to select a household where all the households in a house packed in the same day. Any house where there is only one household, the household was automatically examined.

Household in this case is made of people occupying one dwelling unit and feeding from one pot [12]. The questionnaire was administered to household heads, whether male or female. Household heads refer to the man or woman (usually called husband or wife, [12]). In cases where this does not exist, the bread winner was administered as the household head. The house numbering system in the estates was used in both identifying the houses and administering the questionnaire. The questionnaire seeks principal information on the assessment of basic infrastructure provision (roads, drainages, water supply, electricity supply, sanitary facilities and solid waste disposal facilities) in the public housing estates in Awka. It comprises of a total of fifty-four structured questions. It is divided into two sections. Section A has eleven questions and is structured in such a way to elicit information on the respondents' demographic data as a means of providing background information and also to obtain suitability of the respondent for the study. Section B has six parts but concentrated on basic infrastructure provisions.

The likert scale was used. The likert scale in this questionnaire uses strongly satisfied, satisfied, undecided, dissatisfied and strongly dissatisfied. In other to convert these qualitative responses into a form amenable to quantitative analysis, the use of figures is introduced. Thus 5 -stands for strongly satisfied; 4 - satisfied; 3 undecided; 2- dissatisfied and 1 stands for strongly dissatisfied. One-way analysis of variance (ANOVA) without interaction was used to test the hypothesis.

\section{Results}

A one-way ANOVA was used to test whether there is a significant difference in the levels of residents' satisfaction with the basic physical infrastructure facilities among the housing estates. The general results reveal that there are significant differences even when estates were compared. This implies that there are significant differences in the level of residents' satisfaction with the basic facilities in the estates. The differences in the levels of satisfaction suggest differences in the quantity, quality and maintenance of basic infrastructure facilities provided, indicating that all the estates are not evenly provided with these basic facilities. While some may be comfortable, others may have been searching for relocation having been kept in a neglected area. Public housing estates which are model estates ought not to be treated with sentiments. 


\section{Discussion on research findings}

Housing development goes beyond simple shelter. It includes utilities and services such as roads, drainages, water and electricity. All these place housing as an important factor in general wellbeing of the society. Our public housing estates which are government initiated, planned and managed purpose to provide sufficient and adequate housing to the people ought to be model of housing provision especially in basic infrastructure facilities. The condition of basic infrastructure in our public housing estates especially in Awka calls for great concern.

The status of basic infrastructure (roads, drainage, water and electricity) in the public housing provision were assessed in terms of quantity, quality, maintenance and residents' satisfaction. The findings show that generally, the quantity of these basic infrastructure were fairly adequate but the quality, maintenance and residents' satisfaction were very unsatisfactory. It became clear that most if not all public housing estates were usually provided with enough quantity of basic infrastructure facilities at the inception of the project but due to low quality facilities and poor maintenance culture, these facilities do not last. Thus affecting the level of residents satisfaction with the estate facilities. Field observation shows that some of the facilities provided from the inception especially roads were not of good quality. For instance, roads without pavements and drainage channels but only of earth.

According to $[13,14,15,16,17]$ who worked on residents' satisfaction with the housing environment held the view that the end point of government housing provision should be the satisfaction of the occupants among others. They used a wide range of assessment factors within the housing environment with little disparity and though at different study areas (both within and outside the country) with similar methodology discovered that public housing residents were not satisfied with their housing provision. Even though these studies were carried out many years ago, the findings of this research supports their discovery. It shows that the problem of public housing provision not meeting the residents` basic needs still obtains in our housing estates.

The residents of public housing estates in Awka were strongly dissatisfied with the quality and maintenance of basic infrastructure facilities within their estates. For residents of public housing estates to be dissatisfied with the basic infrastructure facilities which are fundamental to life sustenance, there is no doubt that they will also be dissatisfied with the non-basic physical infrastructure (sewerage, waste disposal, transportation) and social infrastructure (education, health, telecommunication, security, fire-fighting services, socio-cultural, recreation parks, banks and financial institutions, housing and other services). The reason being that the operational function of basic infrastructure facilities has a lot to affect the services of both non-basic physical infrastructure and social infrastructure. In a developing country like ours, residents of housing estates may indicate satisfaction with public housing provision when the basic infrastructure facilities are properly functioning. When good roads, drainage channels, water and electricity are adequately supplied to any community, the people rejoice and praise the government for their effectiveness. Infact, they express satisfaction with their condition of living even when other physical and social infrastructure are not provided. This simply expresses our poverty level and has a lot to speak on our unpreparedness to meet the millennium goals now that these basic infrastructure facilities are neglected. Earlier researchers on residents' public housing satisfaction discovered a level of dissatisfaction with housing provisions even when other variables different from basic infrastructure were considered. Since every commodity is primarily produced to satisfy a need among the consumers, public housing provision should be provided to meet the housing need of the targeted group.

In a similar research by [6] on "Urban Infrastructure and Facilities Management", the paper stresses the indispensable positive roles of infrastructure facilities for Nigeria development. It $x$-rayed the conditions of the basic urban infrastructure provision in Nigeria; the implications of the poor basic infrastructure and their effects in Nigerian economy and the major reforms aimed at addressing dearth of infrastructure provision in the country. To ensure efficiency in the present infrastructure provision, the paper suggested that infrastructure must be managed like a business not a bureaucracy; users and other stakeholders should be given strong voice and real responsibility; and government to budget a sizeable amount for maintenance whose expenditure must be monitored. It is clear that good maintenance culture both by government and individuals is needed to keep the infrastructure in our housing estates functioning. This research discovered that in the area of maintenance individual households contribute as if to say that they are solely responsible. Government has no budget at all for maintenance. No wonder our housing estates are left uncared. This ought not to be.

$[18,19]$ worked on housing maintenance comparing public estates with private estates. While [18] discovered that public estates were better maintained, [19] discovered otherwise. He discovered that in the situation with Lagos State Development and Property Corporation (LSDPC) - public housing estates, the residents are responsible for the maintenance of estate facilities and environment which he noticed resulted in neglect and near decaying both homes and infrastructure in LSDPC. The findings of this research on maintenance generally show that basic infrastructure facilities in the estates are not maintained at all by the government. Individual households collectively bear the burden of maintenance. If private estates are 
maintained more than public estates according to [19], it supports the general view that private investments prosper more than public.

Interviews with both the government agencies responsible for the estates and the residents confirm that residents make contributions to repair or replace basic facilities. This has implications on the general housing condition. Many roads in the estates are left with portholes. Roads that are not provided with drainage channels are faced with erosion problems. This has both created ditches on the roads and structural problem in some building foundations especially in Real estate. Since public water supply was generally arranged by State Water Corporation, every household was left to look for alternative supply until the administrative disruption in the State Water Corporation is settled. Lack of maintenance in electrical facilities did also resulted in blackouts in the estates at nights. The PHCN cannot be relied upon in maintaining their facilities. Individual households resorted to the use of electric generating sets thereby constituting noise and air pollution. The estates are therefore unsafe and unhealthy for living.

[20] wrote on "Housing and Health: Time Again for Public Health Action". The paper was based on the premise that poor housing conditions are associated with a wide range of health implications, including respiratory infections, asthma, lead poisoning injuries and mental health. The paper upheld that addressing housing issues offers public health practitioners an opportunity to consider an important social determinant of health and that public health has long been involved in housing issues. Improvement in housing provision whereby the basic infrastructure facilities are available and adequately maintained for efficient services means improvement in health conditions. Housing environmental quality cannot be detached from neighborhood health quality. For instance, availability of water supply provides the means for environmental cleanliness. The occupants of our public housing estates in Awka are left to provide water for themselves. This results into household judicious water management to the expense of environmental cleanliness. Thus toilets may not be flushed regularly and adequately, dirty drainage channels and concreted building surroundings may not be washed leaving them to form algae and other infections. This can result into an outbreak of epidemic.

[21] examined the potential of implementing "Partnering" in Hong Kong Housing Authority (HKHA) projects for improving quality and the future trend of adopting partnering in the public housing in Hong Kong. It was based on the premise that the recent scandals involving public housing construction in Hong Kong have undermined public confidence and have cast a shadow over the performance of the local construction industry. Their findings show that lack of ethical awareness, lack of partnership with the Hong Kong Housing Authority and the insufficient quality supervision are the most apparent causes of poor quality housing provision. The findings reveal that partnering can possibly improve quality of public housing projects.

This research identified residents' dissatisfaction with the quality of basic infrastructure facilities in the estates. Residents of these estates may have lost confidence in governments' ability to provide satisfactory housing as it were. Since the basic infrastructure facilities provided are of low quality, they do not meet the housing need of the occupants. This can be likened to the case in Hong Kong. The reason may not be attributed to government's inability to release enough fund to put these facilities in place but its management by the agencies responsible. Residents' partnering in public housing projects will assist in improving the quality of housing facilities. The staff of the government agencies responsible for the estates may not be part of the intended occupants and so may not have the commitment and dedication to quality provision in the estates. More so, they are responsible for the supervision and certification of all project works in the estate. The public housing provision should therefore not be a situation of lets provide for them but let's provide for us. This is only possible when the intended residents of the estate are part of those arranging for the provisions.

In a similar research, [22] wrote on "User-Controlled Updating of Existing Housing: A Prime Way to Satisfactory Affordable Housing". The paper dealt with the issue of housing affordability among modest - to middle income households who cannot own (or rent) the home they want for a prize they can afford. He argued that salvation cannot come from construction of new housing which is almost always very expensive but facilitation of user - controlled process of updating the old housing units occupied by such households. The paper explained "Updating" to mean dwelling enlargement (additional bedrooms and additional spaces for new needs), and/or change of layout, treatment of the façade and yard, or the building facilities. The paper stated that this process has been in operation in Israel for over a quarter of a century.

Though the "User-Controlled Updating of Existing Housing" in Israel was meant to provide satisfactory affordable housing among modest - to middle - income households, it indicates the possibility of involving users to make housing provision available and satisfactory. It is apparent that government may not do everything in providing for a comfortable living in view of the challenges emerging from the increased rate of urbanization. The public particularly the residents/users involvement has become inevitable.

[23], put forward the following advantages of public housing: to preserve long-term affordability for low income households; public housing tenants enjoy greater legal protection from eviction and other possible arbitrary landlord actions than residents of subsidized private housing; minority tenants are more likely to be 
admitted to the public housing program than to comparable private sector programs; despite, rhetoric that the private sector is more efficient than the public sector, there is no clear evidence that subsidized private housing is less expensive than subsidized public housing. These advantages cannot be overlooked since housing is an intractable human imperative. Public housing therefore provides a shield from all externalities.

In a way to improve on the public housing provision, [23] did pointed out the problems with public housing programs as follows: many public housing authorities especially the larger ones are not in a good financial position to take on the development of new projects and instead devote themselves to repairing their existing units; poor management practice also seems to prevent a number of public housing authorities from being effective developers and administrators of assisted housing; and some of the public housings problems stem from its poor public image. These problems are very much with us today in our public housing provision. The issue of funding and management problems has persisted from inception. The little fund provided by government for housing provision end up in private pockets resulting to low quality housing provision. This gave public housing a poor public image. However, these problems can be tackled. [23], recommended that expansion of public housing should be seriously considered especially in the area of sponsorship and that community development organizations be viewed as desirable sponsors of public housing. The research feels that while sponsorship is needed to fund public housing as suggested to make for quality provision, residents partnering in both provision and maintenance will assist in both management of fund and satisfactory living.

V. Residents' Partnering in Public Housing Basic Infrastructure Provision and Maintenance.

This research which considers the quantity, quality and maintenance of basic infrastructure provision in the public housing estates in Awka and the level of residents' satisfaction shows that the quantity of basic infrastructure (roads, drainages, water, electricity supply, sanitary and solid waste disposal facilities) were fairly adequate to carry the existing population. The problem lies with the quality and maintenance of these infrastructures and the absence of resident's satisfaction with the facilities. The research noted that different government agencies were responsible for the construction and maintenance of these estates. These agencies also partners with other government agencies directly responsible for the provision of basic infrastructure facilities to equip the estates. Thus the Ministry of Works for the roads and drainages; Power Holding Company for electricity and State Water Corporation, for water facilities and ANSEPA for solid waste. This has been invoked and yet while huge sum of money is spent to provide adequate and satisfactory housing to workers, even the basic infrastructure facilities are faced with many problems. One wonders on the status of non-basic physical infrastructure and social infrastructure facilities in these estates. Provision of housing for low and middle income earners cannot be suspended since the problem of high cost of building materials and increased cost of land still prevails in our nation.

One of the millennium goals is the provision of basic infrastructure facilities (roads, drainages, water, and electricity supply, sanitary and solid waste facilities) to every community both in rural and urban areas. Since the findings of this research were obtained in an urban study area, the status of basic infrastructure facilities in our rural areas must be in question. In other not to be left out, this millennium goal must be pursued with urgency.

In a bid to provide a panacea to the lingering problems of basic infrastructure provision in our public housing estates, this research comes up with a proposal involving residents in housing provision. It presents a flow chart to be followed in every public housing basic infrastructure provision to meet the requirement of quantity, quality, maintenance and residents' satisfaction in housing provision. This research strongly believes that involving residents in basic housing infrastructure provision eliminates the problems of inadequate quantity provision, low quality materials, lack of maintenance culture and residents dissatisfaction. The research discovered that the existing basic infrastructure in the estates was solely being sustained by the communal effort of the residents. If therefore there was a partnering from the inception, the estates would have been models indeed. 


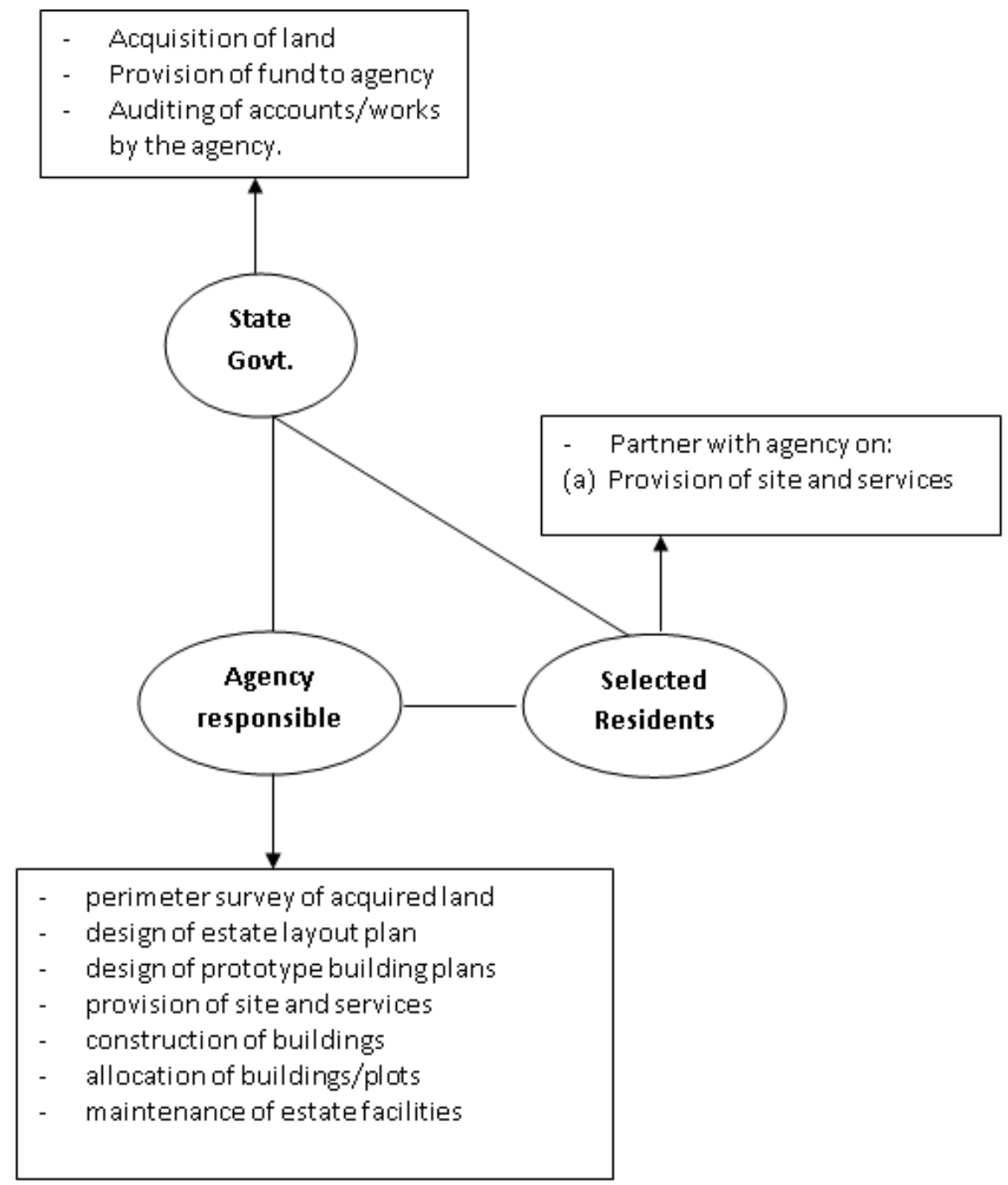

Fig. 1: Flow chart of Residents Partnering in Public Housing Basic Infrastructure Provision and Maintenance

The state government is responsible for the acquisition of land and the provision of funds for estate construction. The funds are made available to the state government agency responsible for the estate. The State Auditor General also audits the accounts and works of the agency regularly.

The agency is responsible for the perimeter survey of acquired land through her survey department, design of estate layout plan through her planning department, design of prototype building plans through her Architectural department, provision of site and services in consultation with the selected residents and with the Ministry of Works - for roads and drainages, Power Holding Company - for electricity and Water Corporation - for water facilities. The agency also supervises the construction of buildings, allocation of buildings/plots to the occupants when completed and maintains the estate facilities in partnership with the selected residents.

The residents to partner with the agency are selected by the agency and approved by the state government. Their number should not be more than seven and should have a chairman and secretary. The selected residents must have indicated interest to live in the proposed estate and must be an identifiable state government worker of not less than Grade level 12 in the service with an educational qualification of not below first degree. The selected residents are responsible to the government and the estate residents and works with the agency. They partner with the agency in provision of site and services and maintenance of estate basic infrastructure facilities. Their operation should be in tenure with renewability of not more than two times.

At the point of completion of estate buildings and facilities and allocations are made to the residents, rents are paid into two different accounts. While $80 \%$ of the rent is paid directly to state government's account, $20 \%$ is paid to the agency responsible for the estate for maintenance. The maintenance department of the agency functions together with the selected residents to keep all facilities in the estate operational.

Estates at the inception should be provided with water facilities like separate borehole, overhead tank and estate electric generating set. The borehole takes care of their water supply while the electric generating set 
provides an alternative electricity supply source. This eliminates the syndrome of individual households owing generating set. Iyiagu housing estate, one of the public housing estates understudies is profiting from this arrangement but still being faced with problems due to the quality of materials provided and the maintenance strategy in place.

\section{Conclusion}

Housing needs have been on the increase in view of the increasing population which merges with low housing stock. The cost of building materials is very exorbitant with a galloping inflationary economy. Workers with their fixed salaries are cut-off from owning a house especially where there are no incentives. The imperative of housing to any household in the face of these harsh economic conditions only encourages corruption for one to survive. Thus the prevailing strategies to eliminate corruption in the country may be difficult to realize seeing that man must be under a shelter with at least some basic infrastructure facilities. It would be difficult for any government to leave public housing provision or to relinquish it to private investors who for profit making will increase the housing problems than solving them. Government's recent intention to sale all public housing properties and off its hands should therefore be revisited. The proposed residents' partnering in public housing basic infrastructure provision and maintenance in this research can be adopted to solve both the problems of quantity, quality, maintenance and residents' satisfaction in public housing provision.

\section{References}

[1] World Bank, World Development Report, 1994: Infrastructure and development, Washington D.C. (World Bank).1994

[2] http://www.worldbank.org/html/fpd/urban/mun-fin/toolkit/strategic-options.html.

[3] R. Masika and S. Basden, Infrastructure and poverty - a gender analysis (Swedish International Development Cooperation Agency, SIDA, 1997)

[4] W. Fox, Strategic options for urban infrastructure management. Urban Management Programme. Policy, Paper 117, Washington, D.C.World Bank. 1997

[5] C. Kessides, The contributions of infrastructure to economic development: a review of experience and policy implication. World Bank discussion paper 213, Washington D.C. World Bank, 1993

[6] M. E. Obiegbu, Urban infrastructure and facilities management, In V. C. Nnodu; C. O. Okoye, and S. U. Onwuka (Eds), Urban environmental problems in Nigeria,( Rex Charles and Patrick limited, Nimo, 2008).

[7] M. N. Oruwari, Housing the urban poor in Nigeria: A reflection of low income provision, An inaugural lecture presented at Rivers State University of Science and Technology, 2006; available at http://www.rsust.edu.ng/presh.html

[8] Nigeria , Federal Government of Nigeria, Third national development Plan (1975 - 80), Federal Ministry of Finance, Lagos. 1975

[9] Nigeria, Federal Government of Nigeria, Fourth national development Plan (1981 - 85), National Plan Office, Lagos. 1981

[10] J. S. Ajanlekoko, Sustainable housing development in Nigeria: The financial and infrastructural implication. A paper presented at the International Conference on Spatial Information for Sustainable Development, Nairobi, Kenya, 2 - 5th October, 2001.

[11] FOS, Social statistics in Nigeria (Federal Office of Statistics, Abuja. 2001)

[12] NPC, 1991 Population Census of the Federal Republic of Nigeria, (National Population Commission, Abuja. 2008)

[13] A. O. Ozo, Low cost urban housing strategies in Nigeria, Habitat International, 14 (1), 1990, $41-54$

[14] L. N. Muoghalu, Consumer satisfaction with public housing: A case study of Riverside Abakpa Nike and Trans-Ekulu housing estate in Enugu, Anambra State, unpublished M.Sc thesis, Department of Geography and Regional Planning, University of Benin, 1982

[15] L. N. Muoghalu, Environmental factors in public housing Satisfaction as potential management data: Lessons from Nigeria", Journal of Environmental Management, London, 19, 1985, 291 - 305

[16] G. C. Galster, and G. W. Hesser, Residential satisfaction: Compositional and contextual correlates. Environment and Behaviour, sage publication, 13 (6), November, 1981, $735-758$.

[17] A. Akinbode, Provision of housing in a newly urbanising area: A case study of Ekpoma, Bendel State, Nigeria", African Urban Quarterly, African Urban Quarterly limited, 4 (1), 1982, 123 - 132.

[18] L. N. Muoghalu, Assessing the magnitude of housing and environmental maintenance needs in a traditional Nigerian City of Benin: A methodological Perspective. A paper presented at the first National Conference on Maintenance Management and Technology, organized by the Faculty of Environmental Sciences, Anambra State University of Science and Technology, Enugu. 1990

[19] G. K. Olusegun, A comparative study of maintenance strategies of public and private housing sstates in Lagos State - case studies of LSDPC housing estate, Iyiagu Ogba and Victoria Garden City, Victoria Island. Unpublished M.Sc. thesis, University of Ibadan, Nigeria, 2002

[20] J. Krieger and L. Higgins, Housing and health: Time again for public health Action", American Journal of Public Health, 92 (5), 2002, $758-768$.

[21] F. K. W. Wong; A. P. C. Chan, and J. M. W. Wong, Partnering - quality policy in public housing”, Journal of Building and Construction Management, 8 (1), 2003, 50 - 59.

[22] N. Carmon, User-controlled updating of existing housing: A prime way to satisfactory affordable housing. A paper presented at the International Research Conference on Adequate and Affordable Housing for All in Toronto, June, 2004.

[23] C. E. Connerly, (1986) What should be done with the public housing programme, Journal of the American Planning Association, Krans Reprint Co., Millwood, New York, 52 (2),1986, 142 - 155 